\title{
Anna Jarmuszkiewicz
}

\section{Retoryka kulturowa jako model recepcji i interpretacji}

W artykule pod tytułem Ukryte założenia i aporie teorii recepcji Katarzyna Chmielewska ${ }^{1}$ zauważa interesującą zasadę, a mianowicie: że badania nad recepcją są uznawane przez ich teoretyków jednocześnie za nowatorskie i tradycyjne $\mathrm{w}$ swoim charakterze, a dodatkowo mają przełamywać „paradygmaty literaturoznawstwa” - poddawać wewnętrznej odnowie historię literatury, stawiać przed badaczami nowe problemy interpretacyjne. Recepcja jest zatem widziana jako problem badawczy o dużym potencjale. Takie postrzeganie recepcji jest związane z faktem, iż samo jej pojęcie ma obecnie bardzo szeroki zakres - obejmuje tłumaczenia, rozważania teoretyczne, a także nawiązania literackie. Pozostaje ciągle pojęciem nieostrym ${ }^{2}$, silnie sprzężonym m. in. z komparatystyką, historią literatury, hermeneutyką, interpretacją i praktyką lekturową. Trudno określić wyraźne jej granice i - jak sądzę - w tym mieści się siła (choć pewnie i słabość) współczesnych badań nad recepcją literacką.

Obecnie w pojęciu „recepcja” mieści się wiele znaczeń. Można przedstawić jej wąskie i szerokie definicje. W pierwszym, zawężonym ujęciu recepcja byłaby zbieżna z niemiecką szkołą estetyki recepcji (reprezentowaną m.in. przez R. Jaussa, W. Isera, H. Weinricha), która - według definicji Michała Głowińskiego - „kwestionując tzw. estetykę wytwarzania i przedstawienia, wysunęła odbiór jako centralny problem badań literackich"3. Ale przytoczona przed chwilą definicja nie będzie stanowić

${ }^{1} \mathrm{~K}$. Chmielewska, Ukryte założenia i aporie teorii recepcji, „Pamiętnik Literacki” 2001/4, s. 5 .

2 Wątpliwości dot. pojęcia, obszaru badań i metody zawarł w krótkim komentarzu A. Skrendo, Recepcja literatury: przedmiot, zakresy, cele badań. Komentarz do tytułu i postscriptum, [w:] Sporne i bezsporne problemy współczesnej wiedzy o literaturze, red. W. Bolecki, R. Nycz, Warszawa 2002.

3 Stownik terminów literackich, red. J. Sławiński, wyd. 4 bez zmian, Wrocław 2002, s. 142 (hasło opracowane przez M. Głowińskiego). 
sedna moich obecnych rozważań - bardziej atrakcyjna dla współczesnych badań jest definicja szersza, której poświęcę kolejną część niniejszego tekstu.

Dzisiejsze badania nad recepcją prowadzone na świecie w starciu z doświadczeniem ponowoczesności rozwinęły różnorodne metajęzyki, sposoby podejścia i metody badawcze. Wśród nich znalazły się m.in. metody instytucjonalne, tekstualne, historyczne, czyli takie, które biorą pod uwagę liczne sposoby, jakimi czytelnicy docierali do tekstów. We współczesnych badaniach dominują odczytania kulturowe, socjologiczne, psychologiczne i - prawie zupełnie nieobecne na polskim gruncie ${ }^{4}$ - badania nad literaturą światową, globalną (F. Moretti, D. Damrosch, P. Casanova).

Współczesne zainteresowanie recepcją wynika - jak wcześniej wspomniałam - z dużej elastyczności ram tego pojęcia. Słownik terminów literackich definiuje recepcję dzieła literackiego w szerszym znaczeniu jako „przyjęcie dzieła literackiego przez publiczność literacką i jej funkcjonowanie wśród różnych grup czytelniczych" ${ }^{5}$. Definicja ta uruchamia w pierwszej chwili przede wszystkim trzy konotacje recepcji: konotację socjologiczną, aksjologiczną oraz lekturową. Jednak owe „przyjęcie” utożsamia się zazwyczaj dość jednoznacznie jedynie z czytaniem, lekturą, a w konsekwencji - z interpretacją literatury. Skutek jest taki, że recepcja zostaje wytrącona ze sfery zainteresowań socjologii i jest przypisana prawie wyłącznie do dziedziny historii literatury.

Amerykańska teoria rezonansu czytelniczego, która nie stanowi jednorodnego nurtu myślowego, uwzględniła poszerzenie terenu badawczego i śmiało wprowadziła do badań recepcyjnych nowe literaturoznawcze dyskursy:

wszystkie zróżnicowane metody badawcze teorii reader-response proponują, aby studia nad recepcją przyjmowały praktyki interpretacyjne XXI wieku, odkąd - oprócz intencji autora - badania literaturoznawcze skupiają się tak na reakcjach czytelnika, na strukturze tekstu i na retoryce, jak również na seksualności, płci, rasie i narodowości autora, czytelnika i społeczeństwa, które odbiera dany tekst ${ }^{6}$.

Podobną sugestię można odnaleźć w artykule Jerzego Madejskiego, który przyznaje, że najciekawsze - dla literaturoznawców - odczytania

4 O badaniach nad literaturą światową pisał R. Nycz, Możliwa historia literatury?, „Teksty Drugie” 2010/5, s. 175-177 oraz M. Delaperrière, E. Grossman, B. Paloff, i R. Cudak w zbiorze pt. Polonistyka bez granic, t. 1, Kraków 2010.

5 Stownik terminów literackich, s. 464.

${ }^{6}$ New Directions in American Reception Studies, red. Ph. Goldstein, J. L. Machor, New York 2008, s. XIII. 
recepcyjne mogą powstać właśnie poprzez działalność przedstawicieli innych dyscyplin (Madejski jako przykład podaje lekturę Szekspira A. Blooma i czytanie dzienników B. Malinowskiego przez J. Clifforda). Pojawia się pokusa transdyscyplinarności. Tym bardziej warto spróbować definicję recepcji uszczegółowić, mocniej wpisać ją w sferę badań kulturowo-społecznych.

\section{Retoryczny wymiar kultury}

Poetyka recepcji wymusza konieczność podkreślania wszelkich rodzajów uwikłania tekstu literackiego w kulturę, jego „naturę kulturową”. Jako że teksty funkcjonują $\mathrm{w}$ ramach wspólnot interpretacyjnych7 - każda interpretacja jest uwarunkowana kulturowo. Recepcja stanowi zatem zbiór takich interpretacji powstałych jako odczytania historyczne (rozłożone w czasie) i jako ślady lektury wspólnot interpretacyjnych, które są nadal i nieustannie realizowane - synchroniczne.

Wywodzące się z kręgu badań neopragmatystycznych pojęcie wspólnot interpretacyjnych nieuchronnie prowadzi do rozpatrzenia przydatności retorycznej hermeneutyki dla teorii recepcji. Steven Mailloux określa „historie recepcji” pojęciem retorycznej hermeneutyki. Amerykański badacz zauważa, że:

teoria reader-response może być postrzegana jako współczesny sposób retorycznego patrzenia na literaturę, gdy podczas lektury analizuje się wszelkie wpływy tekstu na czytelnika (textual effects). W takiej sytuacji badania nad recepcją stają się współczesną perspektywą retoryczną, które skupia się na historycznych wpływach tekstów wywieranych na poszczególnych wspólnotach interpretacyjnych. Podczas badań nad reception histories wykształciłem pojęcie retoryki kulturowej rozumianej jako praktyka efektywności tropów i argumentowania w kulturze [podkreślenie - A. J. $]^{8}$.

Kulturowa retoryka ma więc badać efektywność tropów i argumentowania w kulturze, interpretować funkcję danego tropu (np. metafora czytania jako pochłaniania - utożsamianie tych czynności z jedzeniem) dla historycznie i geograficznie określonej wspólnoty interpretacyjnej. Próbuje uszeregować tropy, chwyt i narracje w tekście i przypisać im kulturowo utrwalone sensy.

7 Pojęcie S. Fisha.

${ }^{8}$ S. Mailloux, Reception histories: rhetoric, pragmatism, and American cultural politics, Ithaca 1998, s. XII. 
Uspołecznienie studiów nad retoryką kulturową musi odnieść swój program do funkcjonowania w takich dziedzinach jak studia feministyczne, badania nad etnicznością i badania nad postkolonializmem. Definiując retorykę kulturową jako społecznie skuteczny trop i argument w kulturze, Mailloux stara się od samego początku włączyć do studiów nad retoryką kulturową badanie kwestii społecznych, np. mechanizmów oporu i dominacji w społeczeństwie wielokulturowym i sugeruje, że badania retoryczne powinny odzyskać swoje, często ignorowane, polityczne (w sensie: uspołecznione) dziedzictwo; powinny też wytworzyć silne zainteresowanie tym projektem zamiast spychać je na margines. Mailloux definiuje retoryczną hermeneutykę poprzez jej działania w przestrzeni kultury: „rhetorical hermeneutics uses rhetoric to practice theory by doing history"9 (retoryczna hermeneutyka stosuje retorykę, aby praktykować teorię przez tworzenie historii).

Już Jerzy Ziomek przyznawal, że retoryka jest „antropologią, a nie tylko normatywnym katalogiem przepisów"10. Stanley Fish poprowadził to twierdzenie dalej sugerując, że nie ma innej antropologii niż retoryczna. Jest to możliwe dlatego, że każdy zretoryzowany tekst jest osadzony we wspólnej przestrzeni kulturowej, która niweluje odległość przestrzenną i czasową, a w ten sposób przybliża dostępność sensów utworu. Retoryka to nie tylko model tworzenia tekstu, ale także sposób jego odczytywania. Chwyty retoryczne, takie jak tropy, figury, toposy sytuują określony utwór w tradycji i - tym sposobem zbliżają do siebie autora i czytelnika, niejako stają się medium, na którym można budować porozumienie. Wtedy retoryka może być postrzegana jako topos, miejsce wspólne, w którym możliwe jest spotykanie nadawcy i odbiorcy. Tak pojmowana retoryka staje się swoistą hermeneutyką - sposobem rozumienia siebie, tekstu literackiego, a także innego. Jednak zrozumienie intencji autora pozostaje jedynie zrozumieniem pewnego chwytu, myślowej rekonstrukcji pewnej metody konstrukcyjnej i nie przekłada się na utworzenie jakiejś wspólnoty doświadczeniowej - pozatekstowej - z autorem. Jednak pisarz, autor utworu, nie posiada innego sposobu na przekaz własnego doświadczenia oprócz możliwości zawarcia go w rozpoznawalnej, przyswojonej przez tradycję, formie.

Napięcia i różnice pomiędzy klasyczną a nowoczesną retoryką precyzyjnie wskazuje w książce pt. Między retoryka a retorycznością Michał Rusinek. Dłuższy cytat pozwoli lepiej te różnice zrozumieć:

9 Tamże, s. IX.

${ }^{10} \mathrm{~J}$. Ziomek, Retoryka opisowa, Wrocław 2000, s. 11. 
W klasycznej [retoryce]:

1. Człowiek jest zwierzęciem rozumnym, żyjącym w społeczeństwie charakteryzującym się społeczną spójnością i ustalonymi wartościami.

2. Nacisk kładzie się na dowody logiczne (racjonalne).

3. Relacja mówca-słuchacze jest antagonistyczna, charakteryzuje się komunikacją jednostronną, manipulacyjną.

4. Celem jest perswazja.

Podczas gdy w retoryce nowoczesnej:

1. Człowiek jest zwierzęciem posługującym się symbolami, żyjącym w społeczeństwie rozczłonkowanym [...].

2. Nacisk kładzie się na emocjonalne (psychologiczne) dowody.

3. Relacja mówca słuchacze ma charakter kooperatywny, charakteryzuje się emfatyczną, obustronną komunikacją.

4. Celem jest komunikacja. ${ }^{11}$

Hermeneutykę retoryzowanego utworu można postrzegać na dwa sposoby: po pierwsze - utwór, poprzez użycie zabiegów retorycznych, a więc czynników uniwersalizujących doświadczenie, jest śladem próby samorozumienia autora (jeśli posłużymy się koncepcją tożsamości narracyjnej); po drugie: czytelnik, jeśli tylko potrafi odczytywać sensy tropów i kod wspólnoty interpretacyjnej, czyli uwarunkowania kulturowe, może w ten sposób jednocześnie zbliżyć się do sensu tekstu, do intencji autora, a wreszcie do samego siebie. Tak rozumiana retoryka staje się retoryczną hermeneutyką - „umożliwia egzystowanie w pewnej wspólnocie interpretacyjnej, która dysponuje absolutną wyłącznością takiego a nie innego rozumienia rzeczywistości"12.

Narracja tworząca tożsamość nie jest kształtowana i wytwarzana „od podstaw", lecz powstaje poprzez wybór z repertuaru wzorców, które są kulturowo akceptowane w danej wspólnocie wzorców. Jednak hermeneutyczny wymiar retoryczności niesie w sobie o czym trzeba pamiętać - ryzyko zaburzenia referencjalności, bo czynnikiem konstytuującym tożsamość jest właśnie retoryczne universum. Dlatego łatwo wyciągnąć wniosek, że w takim układzie tożsamość może zostać zredukowana wyłącznie do tropu, retorycznej figury, gdyż jest wyłącznie modelem lektury, jaki jest akceptowany i realizowany w danej wspólnocie interpretacyjnej. Tożsamość tekstowa pozostaje tylko i wyłącznie tożsamością tekstową.

${ }^{11}$ M. Rusinek, Między retorykq a retorycznością, Kraków 2003, s. 24-25; por. P. Rojek, „Historia zmącana autobiografia”. Zagadnienie tożsamości narracyjnej $w$ odniesieniu do powojennej liryki A. Wata, Kraków 2009, s. 175.

${ }_{12}$ P. Rojek, „Historia zmącana autobiografia”. Zagadnienie tożsamości narracyjnej w odniesieniu do powojennej liryki A. Wata, s. 177. 
W książce Rhetorical Hermeneutics. Invention and Interpretation In the Age of Science pod redakcją Alana G. Grossa i Williama M. Keitha można znaleźć dyskusję (toczącą się pomiędzy Grossem a Dilipem Goankarem), która dotyczy pytania, czy retoryka ma charakter hermeneutyczny. Według Grossa obie - retoryka i hermeneutyka - ujawniają się w tym samym żywiole: retoryka ma określać, jak się wyrażamy, a hermeneutyka - jak rozumiemy.

Gross postuluje, że zamiast retoryki należałoby dziś mówić raczej o retoryczności, czyli o retoryczności poszczególnych dziedzin. Retoryczność według niego to żywioł obecny w świecie życia codziennego (istnieje przecież jako podstawa wszelkiej naukowości ${ }^{13}$ ). Ten stan rzeczy lepiej jest oddawany nowym terminem, jakim jest retoryczność, definiowanym niejako w przeciwieństwie do retoryki.

W interpretacji Grossa używanie retoryki wymusza obecność odbiorcy, co oznacza, że w każdym tego typu działaniu ma się do czynienia z interpretacją. Większość pojęć tradycyjnej retoryki, jak wspomniana imitacja czy dialog, to metafory interpretacji, co ma według Grossa wykazać, że retoryka jest $\mathrm{z}$ góry interpretacyjna. Dlatego badacz może stwierdzić, że nie ma dziś retoryki innej niż hermeneutyczna.

Wydaje się, że konsekwencja takiego toku myślenia jest następująca: retoryka jest hermeneutyczna, więc umożliwia zrozumienie tekstu, intencji autora, siebie samego, bez ograniczeń czasu i przestrzeni. Pozostaje miejscem spotkania dwóch podmiotów: zapisującego $\mathrm{w}$ formie tropów doświadczenie egzystencjalne pisarza i odczytującego retoryczny kod czytelnika. Wykorzystanie retoryki jest jednocześnie wchodzeniem w koło hermeneutyczne i wpisywaniem prywatnego doświadczenia w schematy (tropy, figury...) o charakterze uniwersalnym. Jednak taka hermeneutyka ma ograniczony zakres, gdyż zostaje szczelnie zamknięta w swojej figuratywności - następuje zerwanie referencyjności.

Inaczej problem referencjalności jest rozwiązywany przez Wayne'a Bootha. Wprowadzając figurę implikowanego autora, implied author (określenie, które zostało ukute przez Bootha $\mathrm{w}$ książce The Rhetoric of Fiction ${ }^{14}$ ), Booth stworzył koncepcję pisarza-autora, który „świadomie bądź nieświadomie wybiera, co czytamy; stąd można wnioskować, że jest on literacko stworzoną ideą wersją prawdziwego człowieka; że jest on sumą jego własnych wyborów"15. Badacz twierdzi, że stosowanie określonego typu narracji jest wyborem retorycznym i że autor nie może uniknąć retoryki, może wybrać tylko jeden jej rodzaj/model, którym będzie się

\footnotetext{
${ }^{13}$ Gross podkreśla, że także żargon naukowy posługuje się środkami retorycznymi.

14 W. Booth, The Rhetoric of Fiction, Chicago 1961, s. 70-71.

15 Tamże, s. 74-75.
} 
posługiwał. Autor implikowany odpowiada za wszystkie wybory dotyczące danego dzieła, użycie technik i środków stylistycznych, jest także nadawcą nawiązań intertekstualnych, wątków autotematycznych. Ten wybór jest bardzo wiążący - silnie oddziałuje na czytelnika i jego odbiór literatury. Formy, jakie autor może przybrać, to: osoba gramatyczna, narrator uksztaltowany dramatycznie i nieuksztaltowany dramatycznie ${ }^{16}$.

W The Rhetoric of Fiction amerykański badacz zdecydowanie poddaje w wątpliwość Nową Krytykę, która twierdzi, że można mówić tylko o tym, o czym mówi tekst oraz podważa „nowoczesną krytykę”, która opowiada się za wyplenieniem obecności autorskiej. Booth twierdzi, że nie jest możliwe mówienie o tekście z pominięciem autora, ponieważ fakt istnienia tekstu musi zakładać istnienie jego autora.

Booth nie tylko uważa, że autor, różny od narratora tekstu bądź tożsamy z nim, bezpośrednio ingeruje $\mathrm{w}$ dzieło, że czytelnicy zawsze wywnioskują istnienie autora, kryjącego się za każdym napotkanym tekstem, ale twierdzi także, że czytelnicy wyciągną wnioski na temat przekonań domniemanego autora, równoległych $\mathrm{z}$ różnymi tematami rozwijanymi przez tekst. Dodatkowo Booth zauważa, że bez względu na to jak bardzo autor będzie starał się pozostawać bezosobowym konstruktem, jego czytelnicy nie unikną budowania obrazu oficjalnego skryby, który pisze w ten sposób - i oczywiście ten oficjalny skryba nie będzie neutralny wobec wszelkich wartości.

\section{Retoryka kulturowa a pamięć kulturowa}

Kolejnym zagadnieniem z kręgu zainteresowań recepcyjnych może stać się kategoria pamięci kulturowej, która jest współcześnie bardzo nośna i intensywnie obecna $\mathrm{w}$ badaniach literaturoznawczych. Warto zadać pytanie, czy (i jak?) pamięć kulturowa może być przydatna jako narzędzie w badaniach nad recepcją literacką?

Retorykę kulturową i pamięć kulturową łączy ich kulturowa „kondycja” oraz funkcjonowanie zakorzenienie we wspólnotach. Jak pisze Günter Butzer, „w literaturze europejskiej można wyróżnić dwie «główne» metafory pamięci: metaforę magazynu - przypisywaną mnemotech-

${ }^{16}$ Rozwinięcie tych pojęć można znaleźć w jedynym przetłumaczonym na język polski artykule W. C. Bootha, Rodzaje narracji, przeł. I. Sieradzki, „Pamiętnik Literacki” 1971, z. 1, s. 229-244. Przedruk, [w:] Narratologia, red. M. Głowiński, Gdańsk 2004, s. 212233 i (przypisy) 280-282. 
nice retorycznej, oraz tabliczki woskowej - łączoną z filozofią"17. Kiedy literatura jest postrzegana w świetle pamięci, jawi się przede wszystkim jako sztuka mnemotechniczna. Literatura jest pamięcią kultury nie tylko jako proste „urządzenie do rejestracji”, ale właśnie jako ucieleśnienie upamiętniania, które włącza się w wiedzę przechowywaną przez kulturę i - w zasadzie - wnika we wszystkie teksty, które dana kultura wytworzyła i na których się ukonstytuowała. Pisanie jest jednocześnie aktem pamięci i nowej interpretacji, więc poprzez ten proces każdy nowy tekst może zostać trwale wpisany w przestrzeń pamięci.

Jan Assmann, twórca kategorii pamięci kulturowej, podkreśla hermeneutyczny i urzeczywistniający charakter tradycji tekstualnej, o ile zostaje ona trwale połączona z memoryzacją:

Przejście od oralnego do piśmiennego przekazywania tradycji oznaczało przejście od dominacji powtarzania do dominacji urzeczywistniania, czyli od koherencji rytualnej do tekstualnej. W ten sposób powstała nowa struktura konektywna ${ }^{18}$. Łączy ona i spaja już nie dzięki przechowywaniu i naśladowaniu, lecz dzięki pamięci i interpretacji. Miejsce liturgii zajęła hermeneutyka ${ }^{19}$.

Co istotne, Assmann dość wyraźnie odróżnia pamięć kulturową od tradycji. Rozróżnikiem jest tutaj właśnie element recepcji oraz - w przeciwieństwie do niej - element zapominania. Jeśli dobrze rozumiem myśl Assmanna, tradycja w jego ujęciu ogranicza się do utrwalonego przekazu (zamiast każdorazowej rekonstrukcji całego wspomnienia) o treściach kanonicznych. Natomiast pamięć kulturowa jest bardziej czynna i łatwiej ulega interpretacjom, a także jest bardziej podatna na korozję czasu:

To, co nazywamy pamięcią kulturową i kulturą pamięci, można by, oczywiście, po części opisać jako tradycję lub przekaz, ale opis taki nie uwzględniałby zjawiska recepcji - czyli niwelującego nawiązania, które odbywa się mimo zerwania - oraz jego rewersu - zapominania i wyparcia ${ }^{20}$.

17 G. Butzer, Metaforyka pamięci, [w:] Pamięć zbiorowa i kulturowa. Wspótczesna perspektywa niemiecka, przeł. M. Saryusz-Wolska, red. M. Saryusz-Wolska, Kraków 2009, s. 185.

${ }^{18}$ Struktura konektywna, czyli taka, która ma charakter scalający w przestrzeni społecznej i kulturowej - por. R. Traba, Pamięc kulturowa - pamięć komunikatywna. Teoria i praktyka badawcza Jana Assmanna, [w:] J. Assmann, Pamięć kulturowa. Pismo, zapamiętywanie $i$ polityczna tożsamość $w$ cywilizacjach starożytnych, przeł. A. Kryczyńska-Pham, wstęp i red. R. Traba, Warszawa 2008, s. 14.

19 J. Assmann, Pamięć kulturowa. Pismo, zapamiętywanie i polityczna tożsamość $w$ cywilizacjach starożytnych, s. 34 .

${ }^{20}$ Tamże, s. 50. 
Tak więc literatura to przede wszystkim pisemny nośnik pamięci kulturowej, a pamięć kulturowa łączy się z pamięcią zbiorową. Pojęcie tekstów zbiorowych ma służyć do opisania literatury w jej funkcji „cyrkulacyjnego medium pamięci zbiorowej"21. Teksty literackie często w znacznym stopniu kształtują określone wersje rzeczywistości, obrazy historii i koncepcje tożsamości w obrębie kultur pamięci. Jak w przypadku tekstów kulturowych w ujęciu Jana i Aleidy Assmannów, tak w przypadku tekstów zbiorowych chodzi przede wszystkim o zjawiska przyswajania - rezultat procesu kształtowania konsensusu w pamięciowo-kulturowych wspólnot interpretacyjnych. Jak pisze Astrid Erll:

inaczej natomiast niż w Assmannowskim koncepcie tekstów kulturowych, pojęcie tekstów zbiorowych odwołuje się do zachowań czytelniczych, kiedy to teksty literackie nie są odbierane jako elementy wiążące i obiekty pamięci kulturowej, które należy zapamiętać, lecz jako wehikuły kolektywnej i medialnej konstrukcji oraz transmisji określonej wersji rzeczywistości i przeszłości. Teksty zbiorowe wytwarzają, nadają perspektywę oraz wprowadzają w obieg treści pamięci zbiorowej22.

W przypadku takiej formy odwołania do rzeczywistości nie chodzi jednak o odniesienia na poziomie przednarracyjnego, minionego wydarzenia, lecz o odwołanie do współczesnej pamięci zbiorowej - a zatem do tej szczególnej przestrzeni, która jest konstruowana w sposób symboliczny oraz uformowana przez schematy gatunkowe i odpowiednie typy narracji. Teksty zbiorowe muszą łączyć się ze schematami i wzorami narracyjnymi specyficznymi dla danej kultury oraz $\mathrm{z}$ wyobrażeniami o przeszłości zakorzenionymi we współczesnej kulturze pamięci. Autor znów musi wybierać „własne” elementy z repertuaru tradycji. Astrid Erll pisze, że teksty zbiorowe „mogą służyć jako modele pamięci zbiorowej i modele, które ją projektują. Będąc mediami pamięci zbiorowej, [...] posiadają możliwość konstruowania światów znaczeniowych w «odległym horyzoncie kultury». Struktury opowiadania, symbolika, obrazy Siebie lub Innych mogą być odbierane jako modele dla pamięci kulturowej”23.

Już sam fakt oraz sposób nadawania tekstom funkcji mediów pamięci zbiorowej przez czytelników może w pewnym stopniu zależeć także od ich retoryki. Wszelki odbiór „tekstów zbiorowych” jest skutkiem strategii pisarskiej, którą przywoływana już Erll nazwała „retoryką pamięci zbiorowej":

${ }^{21}$ Por. A. Erll, Literatura jako medium pamięci zbiorowej, [w:] Pamięć zbiorowa i kulturowa. Wspótczesna perspektywa niemiecka, s. 232.

22 Por. tamże, s. 232-233.

23 Tamże, s. 238. 
Retoryka pamięci zbiorowej to zbiór form i działań w obrębie tekstu literackiego, które w znaczeniu potencjału oddziaływania mogą prowadzić do tego, że dany tekst aktualizowany jest przez czytelników jako tekst zbiorowy. Retoryka pamięci zbiorowej znajduje swój wyraz w różnych trybach - tekstualnych zbiorach form ${ }^{24}$.

Intertekstualne uwikłanie w inne utwory, od którego nie jest wolny żaden nowy tekst, odzwierciedla koncepcję pamięci danej kultury, w jakiej utwór funkcjonuje. Pamięć kulturowa stanowi źródło intertekstualnych gier, których nie da się „oszukać”: jakakolwiek tekstowa interakcja w kulturze wielokrotnie powraca w przestrzeni kulturowej, chyba że zostaje zapomniana. Literaturoznawstwo, które postrzega się jako część transdyscyplinarnych badań nad pamięcią, musi zakładać kulturowo-pamięciową kontekstualizację dzieł literackich, nie może opierać się tylko i wyłącznie na kategorii intertekstualności, która czyni założenie, że literatura pamięta sama o sobie, gdyż owe interteksty nie odnoszą się do rzeczywistości pozaliterackiej, lecz jedynie do innych dzieł.

Odpowiedzią na pytanie o przydatność kategorii pamięci kulturowej może być propozycja Renate Lachmann ${ }^{25}$, która wyodrębniła wspólne dla intertekstualności i pamięci kulturowej modele uczestniczenia w kulturze. Są to: 1. partycypacja (participation: udział różnych utworów w dialogu tekstów kultury), 2. tropowanie (troping: trop w rozumieniu Bloomowskim - różne sposoby nawiązań do prekursora), 3. transformacja (transformation: zaangażowania środków z innych tekstów poprzez proces ich dystansowania). Wszystkie teksty uczestniczą, powtarzają i konstytuują akty pamięci. Wszystkie są efektem dystansowania się i przybliżania do prekursora; są widoczne w nich ślady oczywistych nawiązań i elementy nadal niezdefiniowane. Wreszcie wszystkie teksty wykorzystują procedury mnemotechniczne. Jeśli postrzegać konkretne utwory jako „kolekcje intertekstów", wtedy one same w sobie stają się miejscami pamięci.

\section{Bibliografia}

Assmann Jan, Pamięć kulturowa. Pismo, zapamiętywanie i polityczna tożsamość $w$ cywilizacjach starożytnych, przeł. A. Kryczyńska-Pham, wstęp i red. R. Traba, Wyd. UW, Warszawa 2008.

Booth Wayne Clayson, The Rhetoric of Fiction, University of Chicago Press, Chicago 1961. Booth Wayne Clayson, Rodzaje narracji, przeł. I. Sieradzki, „Pamiętnik Literacki” 1971, z. 1. Przedruk, [w:] Narratologia, red. M. Głowiński, słowo/obraz terytoria, Gdańsk 2004.

24 Tamże, s. 241.

25 R. Lachmann, Mnemonic and Intertextual Aspects of Literature, [w:] Media and Cultural Memory, eds. A. Erll, A. Nünning, Berlin-New York 2008, s. 304. 
Butzer Günter, Metaforyka pamięci, [w:] Pamięć zbiorowa i kulturowa. Wspótczesna perspektywa niemiecka, przeł. M. Saryusz-Wolska, red. M. Saryusz-Wolska, Universitas, Kraków 2009.

Chmielewska Katarzyna, Ukryte założenia i aporie teorii recepcji, „Pamiętnik Literacki” 2001/4.

Erll Astrid, Literatura jako medium pamięci zbiorowej, w: Pamięć zbiorowa i kulturowa. Współczesna perspektywa niemiecka, przeł. M. Saryusz-Wolska, red. M. Saryusz-Wolska, Universitas, Kraków 2009.

Lachmann Renate, Mnemonic and Intertextual Aspects of Literature, [w:] Media and Cultural Memory, eds. A. Erll, A. Nünning, Walter de Gruyter, Berlin-New York 2008.

Mailloux Steven, Reception histories: rhetoric, pragmatism, and American cultural politics, Cornell University Press, Ithaca 1998.

New Directions in American Reception Studies, eds. Ph. Goldstein, J. L. Machor, Oxford University Press, Oxford 2008.

Nycz Ryszard, Możliwa historia literatury?, „Teksty Drugie” 2010/5.

Rojek Przemysław, „Historia zmącana autobiografia”. Zagadnienie tożsamości narracyjnej w odniesieniu do powojennej liryki A. Wata, Universitas, Kraków 2009.

Rusinek Michał, Między retoryką a retorycznością, Universitas, Kraków 2003.

Skrendo Andrzej, Recepcja literatury: przedmiot, zakresy, cele badań. Komentarz do tytulu i postscriptum, [w:] Sporne i bezsporne problemy współczesnej wiedzy o literaturze, red. W. Bolecki, R. Nycz, Wyd. IBL PAN, Warszawa 2002.

Stownik terminów literackich, red. J. Sławiński, wyd. 4 bez zmian, Ossolineum Wrocław 2002.

Ziomek Jerzy, Retoryka opisowa, Ossolineum, Wrocław 2000. 